\title{
Molecular analysis of Pseudomonas aeruginosa isolated from clinical, environmental and cockroach sources by ERIC-PCR
}

\author{
Omid Zarei ${ }^{1}$, Leili Shokoohizadeh², Hadi Hossainpour ${ }^{1}$ and Mohammad Yousef Alikhani2 ${ }^{{ }^{*}}$
}

\begin{abstract}
Objective: The objective of this study was to investigate the antibiotic susceptibility, virulence factors and clonal relationship among Pseudomonas aeruginosa isolated from environmental sources, hospitalized patients and the surfaces of cockroaches in the ICUs of four hospitals in Hamadan, west of Iran. A total of 237, 286 and 156 bacterial isolates were collected from clinical, environmental and cockroach sources respectively from May to September, 2017. The antimicrobial susceptibility was determined using disk diffusion method. The virulence factors, exotoxins A, S and $U$ were detected by PCR. The genetic linkage of P. aeruginosa isolates were analyzed by Enterobacterial Repetitive Intergenic Consensus (ERIC)-PCR.

Results: According to our findings, 58 (24.4\%), 46 (16\%) and 5 (3.25) P. aeruginosa were isolated from clinical, environmental and cockroach samples respectively. The MDR phenotypes were detected in 18 (45\%) and 15 (37.5\%) of clinical and environmental strains. The environmental isolates harbored more exoA and exoS than did clinical isolates. Genetic diversity was established among P. aeruginosa isolates as 14 different ERIC fingerprints were detected. The clonal relationships was detected among clinical, environmental and cockroach isolates. Our results highlighted the importance of identifying and controlling the potential sources of $P$. aeruginosa infections in hospitals.
\end{abstract}

Keywords: Pseudomonas aeruginosa, ERIC-PCR, Clinical, Environmental, Cockroaches

\section{Introduction}

Pseudomonas aeruginosa, an aerobic and positive oxidative gram-negative bacterium, is known as one of the most important causes of nosocomial infections especially in the intensive care units (ICU) [1]. This bacterium is not normally pathogenic but creates opportunistic infections in people with a weak immune system such as ICU patients $[2,3]$. It is a ubiquitous organism, especially in environments such as soil, stagnant water, sediment, food, and in hospital settings [4]. Pathogenesis of $P$. aeruginosa is due to the production of several cellular virulence and extracellular factors. The most important extracellular factors of $P$. aeruginosa include exotoxin $\mathrm{S}($ exo $S)$, exotoxin $\mathrm{U}($ exo $U)$, exoenzyme A (exoA),

\footnotetext{
*Correspondence: alikhani43@yahoo.com

2 Department of Microbiology, Faculty of Medicine, Hamadan University of Medical Sciences, P.O box: 6517838678, Hamadan, Iran

Full list of author information is available at the end of the article
}

secretion proteins III, elastase, alkaline protease, and IV protease, each of which has a toxic effect on mammalian cells $[5,6]$. This bacterium accounts for around $13.5 \%$ of the infections of the Gram-negative bacteria in the ICU and is a primary cause of pneumonia associated with the ventilator in the ICU. The release of these bacteria in the ICU is difficult to control as they are resistant to many antibiotics by several mechanisms $[7,8]$.

There are numerous reports of $P$. aeruginosa disease outbreak that is attributed to environmental sources [9, 10]. Insects are known as the most common sources in the transmission, spread, and the number of diseases. Cockroaches can be infected with about 40 different species of vertebrate pathogens under natural or in vitro conditions [11-13]. The bacterial agents are located in different parts of the internal and external body of the cockroach and can survive for days making these insects a proper carrier and distributor of these agents to human [14]. For the purpose of epidemiological studies and to 
study genetic linkages of bacteria, especially in nosocomial infections, common methods of bacterial typing such as antibiotic resistance patterns, phage typing and serotyping have been replaced by molecular methods such as ribotyping, pulse field gel electrophoresis (PFGE) and PCR-based methods [15]. ERIC-PCR technique is one of the PCR-based methods in which the position and number of ERIC sequences which are different in bacteria are used as a genetic marker for bacterial diversity $[15$, 16 .

The objective of this study is therefore to investigate the antibiotic susceptibility, virulence genes and genetic relationship among $P$. aeruginosa strains isolated from clinical, environmental and cockroach sources using ERIC-PCR technique.

\section{Main text Methods \\ Identification of Pseudomonas aeruginosa isolates}

In a cross-sectional study, a total of 237 clinical samples of hospitalized patients in ICUs, 286 environmental samples of ICUs and 156 samples from external body of cockroaches were isolated from the four teaching hospitals in Hamadan, from May to September, 2017.

Pseudomonas aeruginosa isolates were identified and confirmed by conventional microbiological and biochemical tests [17]. Cockroaches were captured manually using Matchbox. Bacteria were isolated from Cockroaches by placing them in a solution containing peptone water. In brief, $500 \mu \mathrm{l}$ of the peptone solution was inoculated in nutrient agar and blood agar plates. The inoculated plates were then incubated aerobically at $35^{\circ} \mathrm{C}$ for $72 \mathrm{~h}$ [18].

\section{Antibiotic susceptibility testing}

The following antibiotics disks (Mast Group Co, UK) were used: gentamicin (GM, $10 \mu \mathrm{g})$, ciprofloxacin (CIP, $5 \mu \mathrm{g}$ ), imipenem (IMI, $10 \mu \mathrm{g}$ ), meropenem (MEN, $10 \mu \mathrm{g}$ ), colistin $(\mathrm{CO}, 10 \mu \mathrm{g})$, and piperacillin (PIP, $10 \mu \mathrm{g})$. Antibiotic susceptibility was determined by disk diffusion method, according to the Clinical and Laboratory Standard Institute (CLSI 2017) guidelines.

\section{DNA extraction and $P C R$}

Genomic DNAs were extracted from $P$. aeruginosa isolates by a commercial DNA extraction kit (Qiagen, Hilden, Germany). Virulence genes including exoA, exoS, and exoU were detected using specific primers as described previously $[19,20]$.

\section{ERIC-PCR}

The total 85 isolates which comprised of 40 clinical isolates, 40 environmental isolates and 5 isolates from cockroaches were selected for molecular typing by
ERIC-PCR. This technique was carried out in a thermocycler (Bio-Rad, Inc. USA) using the primer ERIC (F): 5'-ATG TAA GCT CCT GGG GAT TCAC-3' and ERIC (R): 5'-AAG TAA GTG ACTGGG GTG AGC G3' (Pishgam Biotech Co, Iran) according to the following protocol: initial denaturation $\left(94{ }^{\circ} \mathrm{C}\right.$ for $\left.5 \mathrm{~min}\right)$ followed by 40 cycles of denaturation $\left(91^{\circ} \mathrm{C}\right.$ for $\left.1 \mathrm{~min}\right)$, annealing $\left(25^{\circ} \mathrm{C}\right.$ for $2 \mathrm{~min}$ ), extension $\left(72{ }^{\circ} \mathrm{C}\right.$ for $2 \mathrm{~min}$ ), and a final cycle of extension at $72{ }^{\circ} \mathrm{C}$ for $5 \mathrm{~min}$. The PCR products were loaded on a $2 \%$ agarose gel (Sigma-Aldrich) at $70 \mathrm{~V}$ for $1 \mathrm{~h}$, and the banding patterns were visualized on an ultraviolet illumination.

\section{ERIC-PCR results analysis}

The ERIC patterns were analyzed by online data analysis service (inslico.ehu.es). ERIC profiles were compared using Dice method and clustered by UPGMA program.

\section{Results and discussion}

In view of the importance of $P$. aeruginosa in hospital settings, the antibiotic resistance patterns, virulence factors including exoA, exoU, and exoS and also the genetic linkage of $P$. aeruginosa from clinical, environmental and cockroach samples were investigated. In the current study, 58 (24.4\%) P. aeruginosa isolates from clinical samples, 46 isolates (16.3\%) from the environment of hospitals and 5 (3.2\%) isolates from cockroaches were identified.

The Clinical isolates of $P$. aeruginosa were isolated from clinical samples including urine $(12 ; 20 \%)$, burn wound (9; $15 \%)$, sputum $(6 ; 10 \%)$, blood $(5 ; 8 \%)$, CSF $(4 ; 6 \%)$, eye (3; 5\%) and ear $(1 ; 2 \%)$. The environmental isolates of $P$. aeruginosa were identified in tracheal tube $(8 ; 17 \%)$ ventilator and toilet $(6 ; 13 \%)$, floor $(4 ; 9 \%)$ bed sheet, trash bin and health worker hand (3;6\%), bathtub (2; 4\%), sink, dosing container and keyboard $(1 ; 2 \%)$. Several other factors like the compliance of health care workers have been shown to influence the rate of $P$. aeruginosa hospital-acquired infections, especially in high-risk units like ICUs [21]. In this study, some isolates of $P$. aeruginosa were recovered from hands of physicians and staff of ICUs. These isolates had MDR phenotypes and harbored virulence factors.

The isolation of $P$. aeruginosa from the cockroaches has been reported [22]; P. aeruginosa gets multiplied in the gut of the cockroaches and is then excreted for up to 114 days [21]. We isolated $P$. aeruginosa on the surfaces of cockroaches. P. aeruginosa isolated from cockroaches showed low virulence and antibiotic resistance.

The high-level resistant (55\%) to meropenem was detected among clinical strains. Colistin was identified as the most effective antibiotics against $P$. aeruginosa from different sources. No resistance to antibiotics was 
detected in isolates from cockroaches. Clinical and environmental strains, however, revealed close susceptibility to antibiotics under study. The MDR phenotypes were detected in 18 (45\%) and 15 (37.5\%) of clinical and environmental strains. The results of antibiotic susceptibility testing is shown in Fig. 1.

Pseudomonas aeruginosa isolates showed high-level resistance to many antimicrobial agents. The high rates of clinical and environmental $P$. aeruginosa isolates show the multi-drug resistance (MDR) phenotype. Antibiotic susceptibility pattern of $P$. aeruginosa showed that $45 \%$ and $37.5 \%$ of clinical and environmental isolates were resistant to more than 3 antibiotics from different classes. However, if more antibiotics were checked, MDR isolates also would have been increased. According to our results, carbapenems (e.g., imipenem and meropenem), ciprofloxacin, gentamicin, and piperacillin did not have an effective activity against $P$. aeruginosa isolates. In line with our results, Mobaraki in Iran and Yi Dou in China reported the high-level resistance to ciprofloxacin and increase of multidrug-resistant strains of $P$. aeruginosa [23, 24]. Ding et al. [25] in a Meta-analyses of 50 studies published from 2010 to 2014 investigated antimicrobial-resistant $P$. aeruginosa and reported the varied prevalence of resistance, with high levels of resistance to gentamicin. Gonçalves et al. [26] reported that $73.9 \%$ of $P$. aeruginosa were multidrug-resistant and $43.9 \%$ were resistant to carbapenems. Khosravi et al. also found high-level resistance to gentamicin, ciprofloxacin, meropenem, piperacillin/tazobactam and imipenem, and no resistance to colistin among $P$. aeruginosa strains isolated from burn patients in a burn center of Ahvaz; Southeast of Iran [27].

We also found that there are some limitations in the use of ciprofloxacin, gentamicin and piperacillin, Imipenem and meropenem in $P$. aeruginosa infection therapy. Given the prevalence of resistant $P$. aeruginosa in hospital environments, medical equipment related to patients and hands of healthcare staff is probably serious causes of concern in hospitals. Where the use of $\beta$-lactam, aminoglycoside or quinolone is found to be quite ineffective, the polymyxins, especially colistin, would attract significant attention as antibiotics against MDR strains and as the final alternative treatment $[28,29]$. Resistance to colistin is rarely observed and limited data are reported on the acquired resistance to colistin or other polymyxins. Since Colistin is thought to be the most effective antibiotic against MDR $P$. aeruginosa, the resistance of

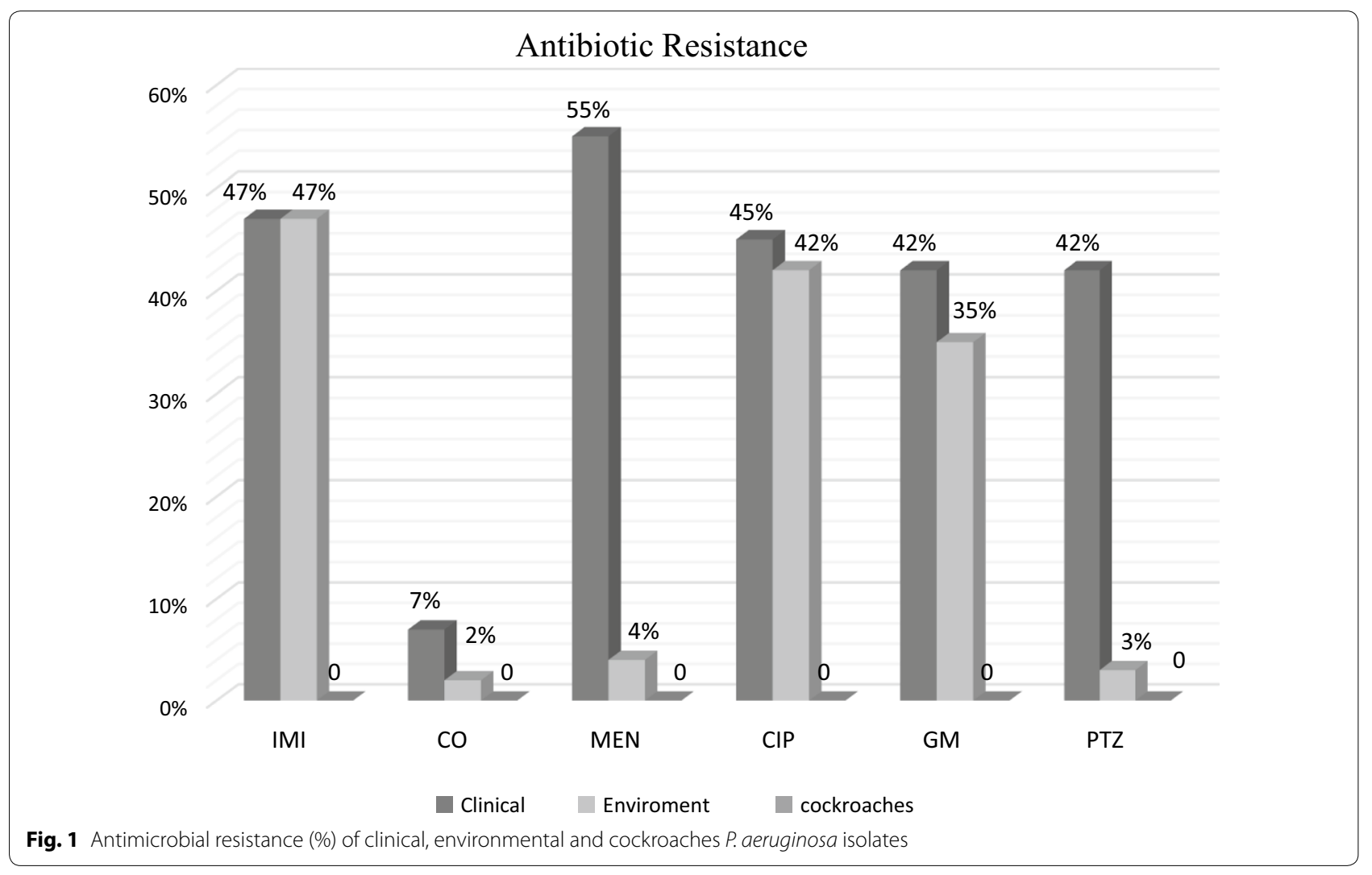


Table 1 Virulence factor frequency in clinical and environmental $P$. aeruginosa isolates

\begin{tabular}{|c|c|c|c|c|c|c|}
\hline Virulence factor & $\begin{array}{l}\text { exoA } \\
\text { No (\%) }\end{array}$ & $\begin{array}{l}\text { exos } \\
\text { No (\%) }\end{array}$ & $\begin{array}{l}\text { exoU } \\
\text { No (\%) }\end{array}$ & $\begin{array}{l}\text { exoA/exoS/exoU } \\
\text { No (\%) }\end{array}$ & $\begin{array}{l}\text { exoA/exos } \\
\text { No (\%) }\end{array}$ & $\begin{array}{l}\text { exoA/exoU } \\
\text { No (\%) }\end{array}$ \\
\hline Clinical isolates & $23(57.5)$ & $13(32.5)$ & $11(27.5)$ & $2(5)$ & $5(12.5)$ & $6(15)$ \\
\hline Environmental isolates & $29(72.5)$ & $29(72.5)$ & $6(15)$ & $1(2.5)$ & $19(47.5)$ & $1(2.5)$ \\
\hline Isolates from cockroaches & $1(20)$ & 0 & 0 & 0 & 0 & 0 \\
\hline
\end{tabular}

$P$. aeruginosa to colistin is increasing leading to serious challenges in the treatment of infections caused by MDR strains of this organism in hospitals, and clinical and environmental sections.

In this research, we studied the presence of three genes encoding virulence factors including exoA, exoU, and exoS in $P$. aeruginosa. The environmental strains harbored more frequent exoA and exoS genes than clinical strains. The frequency of exoU was higher in clinical strains. Only one strain from cockroaches contained exoA gene. The exoA+lexoS + were the predominant (47.5\%) genotype in environmental isolates. The frequency of virulence patterns among $P$. aeruginosa isolates from different sources are compared in Table 1.

There are varied reports on the frequency of exoA, exoU and exoS genes in different studies. Yousefi et al. reported the frequency of exoA, exoU and exoS genes as $90.4 \%, 66.7 \%$ and 65.4 in clinical isolates of $P$. aeruginosa in the South of Iran. Amirmozafar et al. detected the exo A and exoS strains in $81 \%$ and $61 \%$ of clinical isolates of $P$. aeruginosa. According to results from our study and others exoA is a more frequent virulence factor [30-32]. However, it is predominant in environmental isolates and less frequent in clinical isolates. exoU was only found in breathing aid equipment like ventilator and tracheal tube. No exoU was detected in eye infections. There was no significant relationship between virulence genes and clinical specimen type. P. aeruginosa strains possess a highly conserved genome which encodes genes important for survival in numerous environments and allows them to cause a variety of human infections [33].

Analysis of genetic linkage among isolates by ERIC-PCR showed 50-100\% similarity among $P$. aeruginosa isolates (Fig. 2). Genetic diversity was established among P. aeruginosa isolates by detecting 14 different ERIC fingerprints with the similarity cutoff of $\geq 95 \%$. 14 different ERIC profiles, including nine common types and five unique types, were identified. ERIC-type $\mathrm{B}$ as the predominant type comprised 17 isolates (42.3\%) and E-type $\mathrm{K}$ comprised
16 isolates (40\%). E-types $\mathrm{C}$ was shared by clinical isolates (urine and sputum), environmental isolates (tracheal tube and floor) and isolates from cockroaches. One clinical isolate from sputum and one isolate from the surface of cockroaches showed the same antibiotic resistance and virulence genes patterns. E-type $\mathrm{K}$ and $\mathrm{J}$ comprised clinical (burn wound, blood, CSF, urine, and sputum) and environmental (the tracheal tube, physician's hand, sink, and ventilator) isolates. ERIC-type $\mathrm{G}$ was shared by clinical isolates (sputum, CSF, and blood) and isolates from cockroaches (Fig. 2). E-types C, K, and G were identified in the same hospital. This indicated the intra hospital dissemination of these clones. Our results also showed that the variation in the ERIC regions is not closely related to the presence of resistance or virulence genes and there was no significant relationship among antibiotic resistance, virulence gene and ERIC Patterns. We also found that isolates with common ERIC types showed different antibiotic resistance and virulence factor patterns. These findings indicate the presence of various isolates in terms of antibiotic resistance and virulence in hospitals.

Several studies have thus reported genetic diversity and heterogeneity among $P$. aeruginosa isolates using ERICPCR, rep-PCR, RAPD-PCR, PFGE, MLST, DLST methods in hospitals of Iran and other countries [10, 34, 35]. In this study, ERIC-PCR was used since it is much cheaper and easier to perform and adequate reliability, rapidity and discriminatory power have been documented for the typing of $P$. aeruginosa strains through this method [36].

In conclusion, ERIC-PCR analysis showed that there is clonal relatedness among clinical and environmental isolates and isolates taken from cockroaches in the ICUs. Diversity was also found among $P$. aeruginosa isolates in hospitals of Hamadan, Iran. Better understanding of the role of reservoirs in Pseudomonas infections by molecular typing methods would result inn better plans to minimize the transmission of the bacterial infections from patients to the environment and vice versa. 


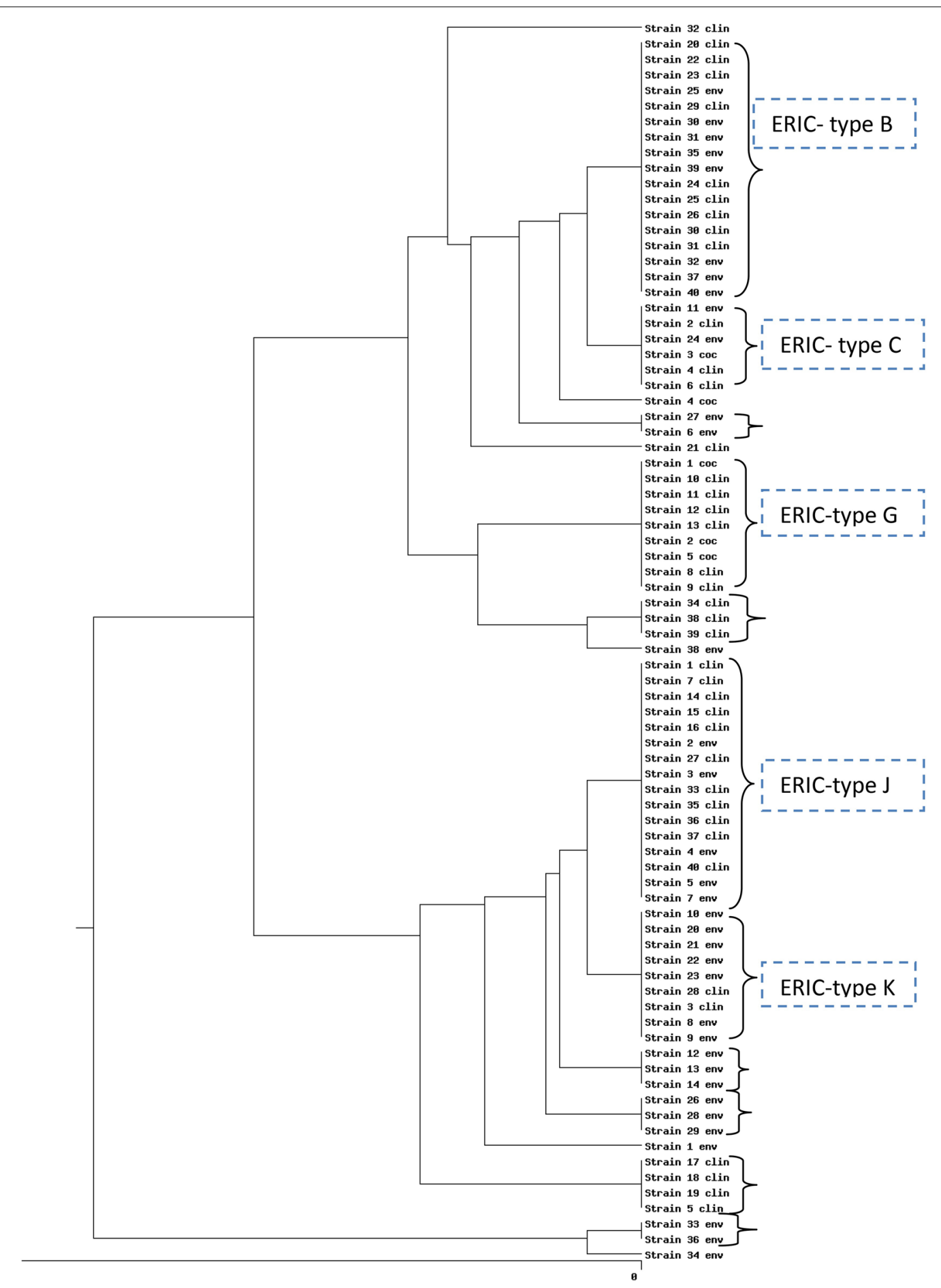

Fig. 2 Dendrogram of ERIC-PCR analysis for 80 clinical and environmental P. aeruginosa isolates and 5 isolates from cockroaches in Hamadan hospitals. E-Type ERIC-Type, clin clinical, env environmental, coc cockroaches 


\section{Limitations}

One of the most important limitations of this study was the low number of $P$. aeruginosa isolated from cockroaches. More sampling is required for molecular studies. We have also limitations in financial support.

\author{
Abbreviations \\ P. aeruginosa: Pseudomonas aeruginosa; MEM: meropenem; IMI: imipenem; \\ CIP: ciprofloxacin; GM: gentamicin; PTZ: piperacillin/tazobactam; CO: colistin; \\ PCR: polymerase chain reaction; exoA: exotoxin A; exoS: exoenzyme S; exoU: \\ exoenzyme $U$.
}

\section{Authors' contributions}

$\mathrm{OZ}$ and MA conceived the study. OZ, LS and HH conducted the experiments and analyzed the results. OZ and LS, drafted the manuscript and made substantial contributions to the design of the study. OZ, MA, and LS, critically reviewed the manuscript. OZ, LS, participated in data analysis. All authors read and approved the final manuscript.

\section{Author details}

${ }^{1}$ Student Research Committee, Hamadan University of Medical Sciences, Hamadan, Iran. ${ }^{2}$ Department of Microbiology, Faculty of Medicine, Hamadan University of Medical Sciences, P.O box: 6517838678, Hamadan, Iran.

\section{Acknowledgements}

We would like to thank all members of microbiology laboratory of Hamadan University of medical science and staff of ICUs in Hamadan hospitals.

\section{Competing interests}

The authors declare that they have no competing interests.

\section{Availability of data and materials}

All the information supporting our conclusions and appropriate references are included in the manuscript.

\section{Consent for publication}

Not applicable.

\section{Ethics approval and consent to participate}

The present study was ethically approved by the Hamadan University of Medical Sciences, Institutional Review Board (IR.UMSHA.REC.1397.62).

\section{Funding}

This research was funded by a grant from Student Research Center of Hamadan University of Medical Sciences, Hamadan, Iran.

\section{Publisher's Note}

Springer Nature remains neutral with regard to jurisdictional claims in published maps and institutional affiliations.

Received: 28 June 2018 Accepted: 5 September 2018

Published online: 15 September 2018

\section{References}

1. Neuhauser MM, Weinstein RA, Rydman R, Danziger LH, Karam G, Quinn JP. Antibiotic resistance among gram-negative bacilli in US intensive care units: implications for fluoroquinolone use. JAMA. 2003;289:885-8.

2. Lyczak JB, Cannon CL, Pier GB. Establishment of Pseudomonas aeruginosa infection: lessons from a versatile opportunist1. Microbes Infect. 2000;2:1051-60.

3. Rusin PA, Rose JB, Haas CN, Gerba CP. Risk assessment of opportunistic bacterial pathogens in drinking water. In: Ware GW, editor. Reviews of environmental contamination and toxicology. New York: Springer; 1997. p. 57-83.
4. Sadikot RT, Blackwell TS, Christman JW, Prince AS. Pathogen-host interactions in Pseudomonas aeruginosa pneumonia. Am J Respir Crit Care Med. 2005:171:1209-23.

5. Khalifa ABH, Moissenet D, Thien HV, Khedher MA. Virulence factors in Pseudomonas aeruginosa: mechanisms and modes of regulation. Ann Biol Clin. 2011;69(4):393-403. https://doi.org/10.1684/abc.2011.0589.

6. de Bentzmann S, Polette M, Zahm J-M, Hinnrasky J, Kileztky C, Bajolet O, Klossek J-M, Filloux A, Lazdunski A, Puchelle E. Pseudomonas aeruginosa virulence factors delay airway epithelial wound repair by altering the actin cytoskeleton and inducing overactivation of epithelial matrix metalloproteinase-2. Lab Invest. 2000;80:209.

7. Cross A, Allen JR, Burke J, Ducel G, Harris A, John J, Johnson D, Lew M, MacMillan B, Meers P. Nosocomial infections due to Pseudomonas aeruginosa: review of recent trends. Rev Infect Dis. 1983;5:S837-45.

8. Ramirez-Estrada S, Borgatta B, Rello J. Pseudomonas aeruginosa ventilatorassociated pneumonia management. Infect Drug Resist. 2016;9:7.

9. Floret N, Bertrand X, Thouverez M, Talon D. Nosocomial infections caused by Pseudomonas aeruginosa: exogenous or endogenous origin of this bacterium? Pathol Biol. 2009;57:9-12.

10. Doleans-Jordheim A, Cournoyer B, Bergeron E, Croize J, Salord H, Andre J, Mazoyer M-A, Renaud F, Freney J. Reliability of Pseudomonas aeruginosa semi-automated rep-PCR genotyping in various epidemiological situations. Eur J Clin Microbiol Infect Dis. 2009;28:1105-11.

11. Davey GC. The" disgusting" spider: the role of disease and illness in the perpetuation of fear of spiders. Soc Anim. 1994;2:17-25.

12. Tatfeng Y, Usuanlele M, Orukpe A, Digban A, Okodua M, Oviasogie F, Turay A. Mechanical transmission of pathogenic organisms: the role of cockroaches. J Vector Borne Dis. 2005;42:129.

13. Foil LD, Gorham JR. Mechanical transmission of disease agents by arthropods. In: Eldridge BF, Edman JD, editors. Medical entomology. Dordrecht: Springer; 2000. p. 461-514. https://doi. org/10.1007/978-94-007-1009-2_12.

14. Gorham J. The significance for human health of insects in food. Annu Rev Entomol. 1979;24:209-24

15. Van Belkum A, Tassios P, Dijkshoorn L, Haeggman S, Cookson B, Fry N Fussing V, Green J, Feil E, Gerner-Smidt P. Guidelines for the validation and application of typing methods for use in bacterial epidemiology. Clin Microbiol Infect. 2007;13:1-46.

16. Ranjbar R, Ghazi FM. Antibiotic sensitivity patterns and molecular typing of Shigella sonnei strains using ERIC-PCR. Iran J Public Health. 2013:42:1151.

17. Sorkh MAG, Shokoohizadeh L, Rashidi N, Tajbakhsh E. Molecular analysis of Pseudomonas aeruginosa strains isolated from burn patients by repetitive extragenic palindromic-PCR (rep-PCR). Iran Red Crescent Med J. 2017;19(4):e43508.

18. Tille P. Bailey \& Scott's diagnostic microbiology-E-book. New York: Elsevier Health Sciences; 2015.

19. Hornef MW, Roggenkamp A, Geiger AM, Hogardt M, Jacobi CA, Heesemann J. Triggering the ExoS regulon of Pseudomonas aeruginosa: a GFPreporter analysis of exoenzyme (Exo) S, ExoT and ExoU synthesis. Microb Pathog. 2000;29:329-43.

20. Salas-Pacheco JM, Setlow B, Setlow P, Pedraza-Reyes M. Role of the Nfo (YqfS) and ExoA apurinic/apyrimidinic endonucleases in protecting Bacillus subtilis spores from DNA damage. J Bacteriol. 2005;187:7374-81.

21. Blanc D, Francioli P, Zanetti G. Molecular epidemiology of Pseudomonas aeruginosa in the intensive care units - a review. Open Microbiol J. 2007;1:8.

22. Saitou K, Furuhata K, Kawakami Y, Fukuyama M. Isolation of Pseudomonas aeruginosa from cockroaches captured in hospitals in Japan, and their antibiotic susceptibility. Biocontrol Sci. 2009:14:155-9.

23. Mobaraki S, Aghazadeh M, Barhaghi MHS, Memar MY, Goli HR, Gholizadeh P, Kafil HS. Prevalence of integrons 1, 2, 3 associated with antibiotic resistance in Pseudomonas aeruginosa isolates from Northwest of Iran. BioMedicine. 2018;8(1):12-7. https://doi.org/10.1051/bmdcn/2018080102

24. Dou Y, Huan J, Guo F, Zhou Z, Shi Y. Pseudomonas aeruginosa prevalence, antibiotic resistance and antimicrobial use in Chinese burn wards from 2007 to 2014. J Int Med Res. 2017:45:1124-37.

25. Ding C, Yang Z, Wang J, Liu X, Cao Y, Pan Y, Han L, Zhan S. Prevalence of Pseudomonas aeruginosa and antimicrobial-resistant Pseudomonas 
aeruginosa in patients with pneumonia in mainland China: a systematic review and meta-analysis. Int J Infect Dis. 2016;49:119-28.

26. Gonçalves IR, Dantas RCC, Ferreira ML, Batistão DWDF, Gontijo-Filho PP, Ribas RM. Carbapenem-resistant Pseudomonas aeruginosa: association with virulence genes and biofilm formation. Braz J Microbiol. 2017:48:211-7.

27. Khosravi AD, Motahar M, Montazeri EA. The frequency of class 1 and 2 integrons in Pseudomonas aeruginosa strains isolated from burn patients in a burn center of Ahvaz, Iran. PloS ONE. 2017;12:e0183061.

28. Li J, Nation RL, Milne RW, Turnidge JD, Coulthard K. Evaluation of colistin as an agent against multi-resistant Gram-negative bacteria. Int J Antimicrob Agents. 2005;25:11-25.

29. Landman D, Georgescu C, Martin DA, Quale J. Polymyxins revisited. Clin Microbiol Rev. 2008;21:449-65.

30. Amirmozafari N, Mehrabadi JF, Habibi A. Association of the exotoxin $A$ and exoenzyme $S$ with antimicrobial resistance. Arch Iran Med. 2016;19(5):353-8.

31. Cotar Al, Chifiriuc MC, Banu O, Lazar V. Molecular characterization of virulence patterns in Pseudomonas aeruginosa strains isolated from respiratory and wound samples. Biointerface Res Appl Chem. 2013:3(2):551-8.
32. Nikbin V, Aslani MM, Sharafi Z, Hashemipour M, Shahcheraghi F, Ebrahimipour $\mathrm{G}$. Molecular identification and detection of virulence genes among Pseudomonas aeruginosa isolated from different infectious origins. Iran J Microbiol. 2012;4:118.

33. Wolfgang MC, Kulasekara BR, Liang X, Boyd D, Wu K, Yang Q, Miyada CG, Lory S. Conservation of genome content and virulence determinants among clinical and environmental isolates of Pseudomonas aeruginosa. Proc Natl Acad Sci. 2003;100:8484-9.

34. Nanvazadeh F, Khosravi AD, Zolfaghari MR, Parhizgari N. Genotyping of Pseudomonas aeruginosa strains isolated from burn patients by RAPDPCR. Burns. 2013;39:1409-13.

35. Cholley P, Stojanov M, Hocquet D, Thouverez M, Bertrand X, Blanc DS. Comparison of double-locus sequence typing (DLST) and multilocus sequence typing (MLST) for the investigation of Pseudomonas aeruginosa populations. Diagn Microbiol Infect Dis. 2015;82:274-7.

36. Wilson LA, Sharp PM. Enterobacterial repetitive intergenic consensus (ERIC) sequences in Escherichia coli: evolution and implications for ERICPCR. Mol Biol Evol. 2006;23:1156-68.
Ready to submit your research? Choose BMC and benefit from:

- fast, convenient online submission

- thorough peer review by experienced researchers in your field

- rapid publication on acceptance

- support for research data, including large and complex data types

- gold Open Access which fosters wider collaboration and increased citations

- maximum visibility for your research: over 100M website views per year

At BMC, research is always in progress.

Learn more biomedcentral.com/submissions 